\title{
Simulation-Based Evaluation of Mechanical Ventilators
}

Device evaluations, particularly those involving lifesupport devices, are extremely important for the verification of a manufacturer's claims. Many new devices receive clearance from the U.S. Food and Drug Administration (FDA) by what is called a $510 \mathrm{~K}$ process. This means that the manufacturer need only demonstrate to FDA reviewers that their product is substantially equivalent to one or more products previously cleared by the FDA (called predicate devices). The problem is that the FDA does not specify any particular type of comparative testing that is to be performed, leaving the methodology to the manufacturer. Hence, caveat emptor - let the buyer beware (and perform their own device evaluations).

In this issue of Respiratory CARE, Koyama et $\mathrm{al}^{1}$ have $^{2}$ done an admirable job of evaluating an often misunderstood feature of pressure control modes: the pressure rise setting. They provide a wealth of information and remind us that ventilators that seem to offer the same functionality have different implementations, and thus show differences in performance. This study provides an opportunity to consider the general topic of simulation-based evaluation of mechanical ventilators, which may be of use to future researchers.

\section{Simulators}

A ventilator must be connected to a load to evaluate its gas-delivery performance characteristics. By load, I mean something with resistance and compliance, resembling a patient's respiratory system. The simplest load is a test lung composed of a rubber bag with a fixed flow resistance at its opening. A more sophisticated example is a simulator, something with variable resistance and compliance that can be used to model a wide variety of respiratory systems (eg, disease states). Finally, the ventilator could be attached to a real respiratory system (animal or human). All of these systems have one thing in common:

Mr Chatburn discloses relationships with IngMar Medical and Drive DeVilbiss Medical.

Correspondence: Robert L Chatburn MHHS RRT RRT-NPS FAARC, Department of Respiratory Therapy, Respiratory Institute Cleveland Clinic, Mail Stop M-56, 9500 Euclid Ave Cleveland, OH 44195. E-mail: chatbur@ccf.org.

DOI: $10.4187 /$ respcare.06267 they can all be described mathematically by a simple version of the equation for the motion of the respiratory system:

See the Original Study on Page 849

$$
P_{\text {vent }}(t)+P_{\text {mиs }}(t)=E \times V(t)+R \times \dot{V}(t)
$$

Where

$$
\begin{aligned}
P_{\text {vent }}(t)= & \text { the change in transrespiratory pressure dif- } \\
& \text { ference (ie, airway opening pressure - body } \\
& \text { surface pressure) as a function of time } t, \\
& \text { measured relative to end-expiratory airway } \\
& \text { pressure, also known as the pressure gener- } \\
& \text { ated by a ventilator during an assisted breath; } \\
P_{\text {mus }}(t)= & \text { ventilatory muscle pressure difference as a } \\
& \text { function of time } t \text { (ie, the theoretical chest } \\
& \text { wall transmural pressure difference that } \\
& \text { would produce movements identical to those } \\
& \text { produced by the ventilatory muscles during } \\
& \text { breathing maneuvers, which would be pos- } \\
& \text { itive during inspiratory effort, negative dur- } \\
& \text { ing expiratory effort); } \\
V(t)= & \text { volume change relative to end-expiratory } \\
& \text { volume as a function of time } t ; \\
\dot{V}(t)= & \text { flow as a function of time } t \text { (ie, the first } \\
& \text { derivative of volume with respect to time); } \\
E= & \text { elastance (change in pressure divided by } \\
& \text { change in volume }[\Delta P / \Delta V], \text { the inverse of } \\
& \text { compliance: } E=1 / C) ; \text { and }
\end{aligned}
$$

In this equation, pressure, volume, and flow are variables, whereas elastance and resistance are parameters (assumed to be constants). This happens to be the same model used by ventilators that calculate and display the resistance and compliance values of patients. Indeed, the graphic waveforms for pressure, volume, and flow displayed by such ventilators are nothing more than the graphical representation of the equation of motion. The compliance $(C)$ of the model is generally assumed to be linear for ventilator-performance studies, in the form of $C=\Delta \mathrm{V} / \Delta \mathrm{P}$. The resistance $(R)$ is modeled as either linear $(R=\Delta \mathrm{P} / \Delta$ flow $)$ or non-linear (eg, parabolic). A parabolic resistor is one for which pressure is proportional to the square of flow. Note that for a parabolic resistor, the resistance is often 
defined as $\Delta \mathrm{P} / \Delta$ flow at a particular flow value. This means that the equivalent linear resistance is different for each flow at which it is evaluated. In other words, when using a parabolic resistor, the resistive load of the model changes as flow changes. Hence, to maintain consistent testing parameters across different flows, it is usually better to select linear resistors rather than parabolic resistors.

Many studies reporting ventilator performance evaluations (including the one by Koyama et al) ${ }^{1-3}$ have used the Michigan Instruments Training and Test Lung (TTL) simulator. This device has one or two spring-loaded bellows to model compliance (adjustable spring tension allows compliance values to vary) connected in series with parabolic flow resistors. The TTL is a passive device. To simulate inspiratory effort, researchers have improvised by linking the two bellows and using one to drive the other by connecting it to a separate ventilator. ${ }^{4}$ Thus, the larger the tidal volume and the higher the inspiratory flow of the drive ventilator, the higher the simulated inspiratory effort. Unfortunately, this procedure limits the shape of the $P_{\text {mus }}(t)$ to the available flow shapes from the drive ventilator, which are quite limited. Koyama et $\mathrm{al}^{1}$ used a sinusoidal flow setting from the drive ventilator to provide a realistic simulation with this type of system.

Recent studies ${ }^{5-10}$ use a more sophisticated device, the IngMar Medical ASL 5000 breathing simulator. This is a computer-driven piston controlled by the equation of motion to model any value of resistance and compliance for either a single- or double-compartment lung model. It can simulate both passive and active breathing. The latter is accomplished by modeling the $P_{\text {mus }}(t)$ waveform (the effort model) in addition to setting the model resistance and compliance (the lung model). The ASL 5000 can display pressure, volume, and flow waveforms in real time, record waveforms for later analysis, and can also calculate a wide range of parameters for ventilator-performance evaluation and comparison. A similar breathing simulator is made by Hans Rudolph (Series 1101 Lung Simulator). ${ }^{11}$

\section{Lung Modeling}

\section{Linear Mechanics}

As mentioned above, the lung model is the component of a simulation that is composed of the flow resistance and elastance. The equation for the motion of the respiratory system described here assumes that $R$ and $C$ are linear, meaning that their pressure-flow and volume-pressure curves are straight lines. This means that $R$ and $C$ remain constant regardless of the volume and flow settings on the ventilator. While real respiratory systems often have nonlinear values for $R$ and $C$, linear models simplify device comparisons. It is possible to construct physical models with fixed linear resistance, ${ }^{12}$ variable linear resistance (see U.S. patent \#4,691,187 issued to George Mon), nonlinear resistance (holes in non-porous material) and fixed or variable compliance (depending on the volume of a rigid-walled container). ${ }^{13}$ This was accomplished prior to the introduction of modern breathing simulators.

\section{Non-linear Mechanics}

Some simulations require non-linear mechanics. One example would be the evaluation of optimal tidal volume and PEEP procedures where changes in lung volume would be expected to change compliance. One method for modeling non-linear resistance was described by Otis et al. ${ }^{14}$ The standard non-linear compliance model has been described by Harris et al. ${ }^{15}$ Recent studies have generated parameter values for the model described by Harris et al ${ }^{15}$ that represent human lungs. ${ }^{16}$ The Hans Rudolph simulator uses constant resistance and compliance values. The IngMar ASL 5000 allows the creation of non-linear resistance and compliance models; unfortunately, the parameters of the non-linear compliance used by that simulator do not match the parameters of the model described by Harris et al, ${ }^{15}$ thus making use of the available human data somewhat difficult.

Some authors have attempted to add the non-linear resistance of an endotracheal tube to a linear resistance representing the airways. This is done by attaching an endotracheal tube between the breathing simulator and the ventilator. ${ }^{6}$ This can result in unexpected difficulties. The simulator is designed to report transrespiratory pressure (or $P_{\text {vent }}$ ) as the pressure at the connection to the simulator opening. With an endotracheal tube interposed, this pressure must now be interpreted as tracheal pressure. This affects all of the calculations the simulator makes under the assumption that it is measuring airway pressure, including work estimates. Furthermore, the lung model resistance, to be realistic, can no longer be referenced to total airway resistance (as found in many human subject studies) and must now represent the resistance from the carina to the alveolar region. This value is seldom if ever available in the literature, weakening the validity of the simulation.

\section{Effort Modeling}

If the study requires that the simulated patient make breathing efforts, we must specify an effort model along with the lung model. The effort model is the mathematical form of $P_{\text {mus }}(t)$ in the given equation. Most often, this is assumed to be generally sinusoidal, which is why Koyama et $\mathrm{al}^{1}$ chose a sinusoidal flow waveform to power the drive lung in their simulation. The Hans Rudolph and IngMar simulators allow a sinusoidal $P_{m u s}(t)$ waveform with variable frequency and variable pressure rise and fall times (yielding an inspiratory-expiratory ratio [I-E]). However, 


\section{EDITORIALS}

determining realistic values for these parameters (aside from frequency) is a challenge. There has been only one study that actually measured $P_{\text {mus }}(t)$ in ventilated subjects. ${ }^{17}$ Otherwise, realistic I-E ratios may be derived from studies that measure esophageal pressure or the electrical signal of the diaphragm (eg, neurally adjusted ventilatory assist).

The amplitude of $P_{\text {mus }}(t)$ is set arbitrarily. Some researchers like to set it to generate occlusion pressures (ie, pressure at $10 \mathrm{~ms}$ after initiation of effort $\left[\mathrm{P}_{0.1}\right]$ ) to values that indicate various levels of central ventilatory drive. The problem is that these values are not intuitively appealing because they have no clinical correlates. Rather, I suggest setting the $P_{\text {mus }}(t)$ I-E ratio and then adjusting the amplitude of $P_{\text {mus }}(t)$ to achieve $50 \%$ or $75 \%$ of an unassisted tidal volume. That way you can say the patient made a $50 \%$ or $75 \%$ effort (alternatively, the patient needs $50 \%$ or $25 \%$ assistance from the ventilator). As you can see, this is still unexplored territory for simulation designers.

\section{Realistic Simulation Parameters}

Simulations must be designed with realistic, evidencebased parameters. Simulation parameters have a large effect on experimental outcomes, which means that unrealistic parameters yield unreliable results. In fact, simulation parameters can be deliberately selected to bias outcomes in a particular manner. An unfortunate fact about ventilator-performance studies is that there is no consistency among researchers regarding the selection of lung model parameters. This makes it impossible to aggregate data across studies. There have been some standards that were intended for manufacturers to use for product testing, namely ASTM F 1100-90 Standard Specification for Ventilators Intended for Use in Critical Care. For example, the ASTM standard specifies both linear and parabolic resistance values and linear compliance values to represent adults, children, and infants. There are, however, several problems with this standard. First, the values for $R$ and $C$ are not referenced in any way to actual data from human studies; in other words, they are not evidence-based. Second, the values are referenced to patient age, not disease type, whereas many ventilatorperformance studies attempt to simulate disease states like ARDS and COPD. Third, parabolic resistors may bias results as mentioned above. Finally, the standard was withdrawn by the ASTM without replacement in 2004. Researchers are thus left to their own opinions about model parameter values, and few, if any, provide justification for their selections. ${ }^{18}$

A recent paper by Arnal et al ${ }^{19}$ has addressed this issue and provided data for constructing standardized linear (passive) adult respiratory system models for simulation-based ventilator evaluations. Dexter et $\mathrm{al}^{20}$ have published similar data for pediatric models.

\section{Practical Outcome Variables}

\section{Volume and Flow}

Many ventilator evaluation studies report volume and flow data. Such measurements are fraught with complications, especially when the intent is to compare the ventilator-derived volume and flow measurements with independent accepted standard measurement devices. The complications have to do with the fact that volumes displayed by the ventilator will differ from those displayed by independent measuring devices for two basic reasons: (1) ventilators use complicated proprietary algorithms to compensate for gas compressed in the delivery tubing, ${ }^{21}$ and (2) gas temperature and water vapor corrections. ${ }^{22,23}$ Many papers attempting to report ventilator display "errors" have ignored these important sources of confounding effects.

\section{Pressurization}

During pressure control modes of ventilation, the pressure waveform is often idealized as having a rectangular or square shape. Real ventilators, however, often produce a slight pressure overshoot due to the fact that no ventilator is a perfect pressure controller (ie, there are trade-offs between optimal waveform damping and optimal flow delivery). This was noted by Koyama et al, ${ }^{1}$ who state, "If higher pressurization (rate) is applied to patients with high impedance, an overshoot of the airway pressure may likely occur." Monitoring peak pressure is important in volume control modes, but it is a nuisance in pressure control modes because, in the case of an overshoot, the ventilator will display a peak pressure that differs from the set inspiratory pressure target, potentially creating confusion among clinicians. Despite the fact that the small and very brief pressure overshoot seldom (if ever) reaches the alveolar regions of the lungs, clinicians frequently try to eliminate it by increasing the pressure rise time. This decreases both peak inspiratory flow and tidal volume, however, as demonstrated in the study by Koyama et al. ${ }^{1}$ The simple solution would be to eliminate the peak pressure display during pressure control ventilation and not worry about overshoot if maximum flow is desired.

\section{Pressure-Time Product}

The rate of pressurization affects the area under the inspiratory pressure-time curve such that the faster the pressurization, the larger the area for a given inspiratory time. Hence, many researchers use the pressure-time product (PTP), which is the area under the pressure-time curve 


\section{EDITORIALS}

for a specified portion of the inspiratory time, as an index of pressurization. There are potential problems with this metric. First, it can be confused with the PTP defined as a metric of respiratory work or the oxygen cost of breathing. ${ }^{24}$ Second, the numbers that are reported for PTP as a metric of pressurization are difficult to appreciate intuitively because they have no clinical meaning. Finally, PTP includes any pressure overshoot, potentially making it a less sensitive metric when comparing pressure waveforms.

\section{P90}

An alternative to PTP is the P90, which is the time for the pressure to rise from baseline to $90 \%$ of the peak value. Defining a metric in this way has a straightforward interpretation that is easy to visualize and eliminates contamination by overshoot oscillations. In addition, if 10\%-90\% is used, it also eliminates any noise around the start of inspiration. This metric is also easier to calculate by hand than the PTP.

\section{Final Thoughts}

Review of the study by Koyama et $\mathrm{al}^{1}$ affords us the opportunity to look at a larger issue that plagues health care, and indeed our whole society. Ventilator technology has developed at an exponential rate in the last 20 years, from simple analog devices with 2-3 modes of ventilation to complex digital computer-driven ICU machines with several dozen modes and features like pressurization adjustment that modify performance within a given mode. During this time, however, our understanding of how to use this complexity has progressed slowly and linearly, creating an ever-increasing knowledge gap.

We should be asking ourselves two important questions. First, what is the main limitation in the improvement in outcomes for patients requiring mechanical ventilation? Second, what is the main limitation of mechanical ventilators themselves? For the first question, I suggest that we need to examine the belief that there is any association between the technology of ventilation and patient outcomes. Certainly such a belief exists, as demonstrated in a recent statement by Gattinoni et al: "The ventilator's settings include tidal volume, pressure, respiratory rate, and flow. All these components have been found able to influence [ventilator-induced lung injury], obviously depending on their extent." 25 Intuitively that makes sense, but which settings (or combinations of settings)? If outcomes are the cumulative result of the ventilator settings for individual patients over time, and ventilator settings are the result of specific decisions of individual clinicians at the bedside, then clearly the rate-limiting factor is the knowledge of individual clinicians and the lack of continuity of such decisions over time. If you have ever examined a series of ventilator changes over the course of ventilation for a given patient, the inconsistency and lack of charted evidence for specific decisions becomes painfully obvious.

What is the solution? First, we should make the best use of the information we have. We know that even the simple, evidence-based, lung-protective strategies are practiced by a minority of clinicians. ${ }^{26,27}$ In one survey, more than one third of all patients with ARDS received a tidal volume of $>8 \mathrm{~mL} / \mathrm{kg}$ predicted body weight, and $\sim 60 \%$ received a tidal volume of $>7 \mathrm{~mL} / \mathrm{kg} .{ }^{28}$ This is alarming, given that one study estimated that an increase of $1 \mathrm{~mL} / \mathrm{kg}$ in initial tidal volume was associated with a $23 \%$ increase in ICU mortality risk. ${ }^{29}$ In a recent paper, Morris ${ }^{30}$ provides a stunning exposé of why clinicians do not consistently apply care on the basis of best evidence, and suggests that detailed context-sensitive computer protocols can generate personalized medicine instructions that are well matched to individual patient needs.

One solution to the problem of optimal ventilator design and management is to move away from unreliable decisions by humans toward algorithm-based decisions guided by artificial intelligence (AI) programs. AI is being applied to mechanical ventilation. ${ }^{31,32}$ While promising, these approaches have limited clinical acceptance and are limited to data gathered from one patient at a time. More successful AI, like IBM's Watson or Google's Alpha Zero, use deep learning provided by artificial neural networks that digest vast amounts of dynamic big data. Thinking futuristically, applying this approach to the field of mechanical ventilation would mean that ventilators may devolve into "dumb terminals" (pneumatic hardware and basic control electronics only) connected by the Internet of Things and feeding patient data from all related devices to a central controller with AI designed to learn from the experience of every ventilated patient and continually evolve better means of optimizing settings. ${ }^{33}$ At some point in the future, a ventilator might have only one switch (on/off) and one display (connect/disconnect).

Needless to say, respiratory therapists will have to evolve into more advanced caregivers to understand the functionality of AI technology and provide the health care team with information on patient ventilator performance.

Robert L Chatburn MHHS RRT RRT-NPS FAARC Department of Respiratory Therapy Respiratory Institute Cleveland Clinic Cleveland, Ohio

\section{REFERENCES}

1. Koyama Y, Uchiyama A, Yoshida J, Yoshida T, Yamashita T, Fujino $\mathrm{Y}$. A comparison of the adjustable ranges of inspiratory pres- 


\section{EDITORIALS}

surization during assisted pressure-controlled ventilation mode of 5 ICU ventilators. Respir Care 2018;63(7):849-858.

2. Blakeman TC, Branson RD. Evaluation of 4 new generation portable ventilators. Respir Care 2013;58(2):264-272.

3. Wallon G, Bonnet A, Guerin C. Delivery of tidal volume from four anaesthesia ventilators during volume-controlled ventilation: a bench study. Br J Anaesth 2013;110(6):1045-1051.

4. Blakeman TC, Rodriquez D Jr, Hanseman D, Branson RD. Bench evaluation of 7 home-care ventilators. Respir Care 2011;56(11):17911798.

5. Vasconcelos RS, Sales RP, de P Melo LH, Marinho LS, Bastos VP, Nogueira AdN, et al. Influences of duration of inspiratory effort, respiratory mechanics, and ventilator type on asynchrony with pressure support and proportional assist ventilation. Respir Care 2017; 62(5):550-557.

6. Itagaki T, Chenelle CT, Bennett DJ, Fisher DF, Kacmarek RM. Effects of leak compensation on patient-ventilator synchrony during premature/neonatal invasive and noninvasive ventilation: a lung model study. Respir Care 2017;62(1):22-33.

7. Itagaki T, Bennett DJ, Chenelle CT, Fisher DF, Kacmarek RM. Performance of leak compensation in all-age ICU ventilators during volume-targeted neonatal ventilation: a lung model study. Respir Care 2016;62(1):10-21.

8. Volsko TA, Hoffman J, Conger A, Chatburn RL. The effect of targeting scheme on tidal volume delivery during volume control mechanical ventilation. Respir Care 2012;57(8):1297-1304.

9. Mireles-Cabodevila E, Chatburn RL. Work of breathing in adaptive pressure control continuous mandatory ventilation. Respir Care 2009; 54(11):1467-1472.

10. Chatburn RL, Mireles-Cabodevila E, Sasidhar M. Tidal volume measurement error in pressure control modes of mechanical ventilation: a model study. Comput Biol Med 2016;75:235-242.

11. Chen Y, Cheng K, Zhou X. Performance characteristics of seven bilevel mechanical ventilators in pressure-support mode with different cycling criteria: a comparative bench study. Med Sci Monit 2015;21:310-317.

12. Saklad M, Weyerhaeuser R. The construction of linear resistances for the testing of ventilators. Anesthesiology 1980;52(1):71-73.

13. Hill DW, Moore V. The action of adiabatic effects on the compliance of an artificial thorax. Br J Anaesth 1965;37:19-22.

14. Otis AB, Fenn WO, Rahn H. Mechanics of breathing in man. J Appl Physiol 1950;2(11):592-607.

15. Harris RS, Hess DR, Venegas JG. An objective analysis of the pressure-volume curve in the acute respiratory distress syndrome. Am J Respir Crit Care Med 2000;161(2 Pt 1):432-439.

16. Pereira C, Bohe J, Rosselli S, Combourieu E, Pommier C, Perdrix $\mathrm{JP}$, et al. Sigmoidal equation for lung and chest wall volume-pressure curves in acute respiratory failure. J Appl Physiol (1985) 2003;95(5): 2064-2071.

17. Kondili E, Alexopoulou C, Xirouchaki N, Vaporidi K, Georgopoulos D. Estimation of inspiratory muscle pressure in critically ill patients. Intensive Care Med 2010;36(4):648-655.
18. Chatburn RL. Simulation studies for device evaluation. Respir Care 2014;59(4):e61-e66.

19. Arnal JM, Garnero A, Saoli M, Chatburn RL. Parameters for simulation of adult patients during mechanical ventilation. Respir Care 2017;63(2):158-168

20. Dexter A, McNinch N, Kaznoch D, Volsko TA. Validating lung models using the ASL 5000 breathing simulator. Simul Healthc 2018; 13(2):117-123.

21. Sanborn WG. Microprocessor-based mechanical ventilation. Respir Care 1993;38(1):72-109.

22. Duchateau P, Guerin C. Tidal volume delivery from ICU ventilators at BTPS conditions: a bench study. Respir Care 2013;58(4):623-632.

23. Lyazidi A, Thille AW, Carteaux G, Galia F, Brochard L, Richard JC. Bench test evaluation of volume delivered by modern ICU ventilators during volume-controlled ventilation. Intensive Care Med 2010; 36(12):2074-2080.

24. Nathan SD, Ishaaya AM, Koerner SK, Belman MJ. Prediction of minimal pressure support during weaning from mechanical ventilation. Chest 1993;103(4):1215-1219.

25. Gattinoni L, Tonetti T, Quintel M. Intensive care medicine in 2050: ventilator-induced lung injury. Intensive Care Med 2017; 44(1):76-78

26. Weiss CH, Baker DW, Tulas K, Weiner S, Bechel M, Rademaker A, et al. A critical care clinician survey comparing attitudes and perceived barriers to low tidal volume ventilation with actual practice. Ann Am Thorac Soc 2017;14(11):1682-1689.

27. Weiss CH, Baker DW, Weiner S, Bechel M, Ragland M, Rademaker A, et al. Low tidal volume ventilation use in acute respiratory distress syndrome. Crit Care Med 2016;44(8):1515-1522.

28. Bellani G, Laffey JG, Pham T, Fan E, Brochard L, Esteban A, et al. Epidemiology, patterns of care, and mortality for patients with acute respiratory distress syndrome in intensive care units in 50 countries. JAMA 2016;315(8):788-800.

29. Needham DM, Yang T, Dinglas VD, Mendez-Tellez PA, Shanholtz C, Sevransky JE, et al. Timing of low tidal volume ventilation and intensive care unit mortality in acute respiratory distress syndrome. A prospective cohort study. Am J Respir Crit Care Med 2015;191(2): 177-185.

30. Morris AH. Human cognitive limitations. Broad, consistent, clinical application of physiological principles will require decision support. Ann Am Thorac Soc 2018;15(Suppl 1):S53-S56.

31. Arnal JM, Garnero A, Novotni D, Corno G, Donati SY, Demory D, et al. Closed loop ventilation mode in intensive care unit: a randomized controlled clinical trial comparing the numbers of manual ventilator setting changes. Minerva Anestesiol 2018;84(1):58-67.

32. Rees SE, Karbing DS. Determining the appropriate model complexity for patient-specific advice on mechanical ventilation. Biomed Tech (Berl) 2016;62(2):183-198.

33. Chatburn RL. Classification of mechanical ventilators and modes of ventilation. In: Tobin MJ, editor. Principles and practice of mechanical ventilation. New York: McGraw Hill Medical; 2013:45-64. 